\title{
Einbau von radioaktivem Phosphor in das Virus der klassischen Geflügelpest
}

\author{
Von Eberhard Wecker und Werner SchäFer \\ Aus dem Max-Planck-Institut für Virusforschung, Tübingen \\ (Z. Naturforschg. 11 b, 181-187 [1956]; eingegangen am 30. Januar 1956)
}

\begin{abstract}
Der Einbau von ${ }^{32} \mathrm{P}$ in das Virus der klassischen Geflügelpest gelingt, wenn man den Erreger in Gewebekulturen aus Hühnerembryonal-Zellen züchtet, denen radioaktiver Phosphor zugesetzt wurde. Es werden auf diese Weise relativ hohe spezifische Radioaktivitäten bis zu etwa 1500 Impulse/Min./hämagglutinierender Einheit erreicht. Das Isotop wird bei diesem Züchtungsverfahren zu etwa $21 \%$ in die Ribonucleinsäure, zu etwa $65 \%$ in die PhosphorLipoide des Virus eingebaut.
\end{abstract}

$\mathrm{D}$ urch Untersuchungen mit Bakteriophagen, die durch Einbau von radioaktiven Isotopen gekennzeichnet waren, konnten wesentliche Aufschlüsse über den Vermehrungsmechanismus dieser Viren gewonnen werden. Es lag nahe, auch bei tierpathogenen Virusarten in ähnlicher Weise vorzugehen.

Derartige Versuche scheiterten bisher daran, daß keine ausreichenden Mengen von Isotopen in diese Erreger eingebaut werden konnten. Beim InfluenzaVirus gelang es zwar $\mathrm{Graham}$ und $\mathrm{McClel}$ l a $\mathrm{d}^{1}$ und später $\mathrm{H}$ oy $\mathrm{le}^{2}$ unter Verwendung von bebrüteten Hühnereiern, denen sie radioaktives Phosphat injizierten, ${ }^{32} \mathrm{P}$-haltiges Virus zu züchten. Die spezifische Aktivität der gewonnenen Viruspräparate war aber sehr gering. Eine bessere Markierung des gleichen Erregers erreichten Liu und Mitarbb. ${ }^{3}$. Sie züchteten das Virus in Gegenwart von ${ }^{32} \mathrm{P}$ nicht im embryohaltigen, sondern im entembryonierten Ei.

Das Virus der klassischen Geflügelpest (KP), das in den letzten Jahren eingehender von uns untersucht wurde (Lit. l. c. ${ }^{4}$ ), läßt sich gut in Kultıren aus Hühnerembryonalgewebe züchten*, die in der Hauptsache aus Fibroblasten bestehen. Es wurde versucht, unter Verwendung dieser Züchtungsmethode eine hochgradige Markierung des genannten Erregers mit ${ }^{32} \mathrm{P}$ zu erreichen.

1 A. F. Graham u. L. M c Clelland, Can. J. Res. 28, 121 [1950].

2 L. Hoyle, B. Jolles u. R. G. Mitchell, J. Hyg. 52, 119 [1954].

3 O. C. Liu, H. B lank, J. Spizizen u. W. $\mathrm{H}$ e n le, J. Immunology 73, 415 [1954].

4 W. S chäfer u. W. Zillig, Z. Naturforschg. 9 b, 779 [1954].

* Chr. Lands ch ütz, in Vorbereitung.

\section{Material und Methoden}

1. Gewebekultur

Zur Herstellung der Gewebekultur wurden 10 Tage alte Hühnerembryonen nach dem von D u l be c c o ${ }^{5}$ beschriebenen Verfahren präpariert und die Zellen dann in Petrischalen oder Fernbachkolben angezüchtet. Je Petrischale wurden etwa 8 Millionen Zellen mit $12 \mathrm{ml} \mathrm{Nähr-}$ medium angesetzt, je Fernbachkolben $70 \mathrm{ml}$ Zellsuspension der gleichen Konzentration. Das Nährmedium hatte folgende Zusammensetzung:

9,5 ml Earle-Lösung,

$0,5 \mathrm{ml}$ Embryonalextrakt,

2,0 $\mathrm{ml}$ Pferdeserum (Behring).

2. Virus und Virus-Teste

Virusstamm: Es wurde ausschließlich der Stamm „Rostock“ des KP-Virus verwendet, der bei uns in HühnereiPassagen fortgeführt wird. Er durchlief während der Versuche die 60.-70. Eipassage.

Infektionstest: Die Bestimmung der infektiösen Einheiten erfolgte mit dem von $\mathrm{Dulbeco^{5 }}$ beschriebenen Plaque-Verfahren. Dazu wurden wiederum in Petrischalen Schichten aus embryonalen Hühnerzellen gezüchtet und diese dann mit $0,5 \mathrm{ml}$ fallender Konzentrationen (Verdünnungen nach Potenzen von 10 mit gepufferter NaCl-Lösung, $\left.p_{\mathrm{H}} 7,2\right)$ des zu prüfenden Materials infiziert. Mit jeder Verdünnungsstufe wurden mindestens 3 Petrischalen beimpft und später die plaquebildenden Einheiten (PBE) ausgezählt.

Hämas,glutinations-Test (HA-Test): Zur Auswertung der häm agglutinierenden Aktivität verdünnten wir das Untersuchungsmaterial mit gepufferter NaCl-Lösung nach Potenzen von 2 und setzten dann zu $0,5 \mathrm{ml}$ dieser Verdünnungen einen Tropfen gewaschener Hühnererythrocyten (etwa $6 \cdot 10^{7}$ Blutkörperchen) hinzu. Das Ergebnis wurde nach 30 Min. langem Stehen der Ansätze bei Zimmertemperatur abgelesen ${ }^{6}$. Die Zahl der hämagglutinie-

5 R. Dulbecco, Proc. nat. Acad. Sci. USA 38, 747 [1952].

6 J. E. S a l k, J. Immunology 49, 87 [1947]. 
renden Einheiten (HAE) entspricht dem reziproken Wert der Virusverdünnung, die noch eine deutlich sichtbare $(++)$ Hämagglutination erzeugte.

3. ${ }^{2} \mathrm{P}$ und Bestimmung der Radioaktivi $t \ddot{a} \mathrm{t}$

Sämtliche ${ }^{32}$ P-Präparate wurden vom Isotopenlaboratorium der Medizinischen Forschungsanstalt der MaxPlanck-Gesellschaft in Göttingen als trägerfreies OrthoPhosphat in verdünnter $\mathrm{HCl}$ bezogen. Die Messung der Radioaktivität erfolgte mit einem $\alpha / \beta$-Glockenzählrohr mit Endfenster und einer Glimmerfolie von $1,8 \mathrm{mg} / \mathrm{cm}^{2}$. Der Abstand der zu messenden Präparate von der Glimmerfolie betrug $15 \mathrm{~mm}$. Zählrohr (Typ FHZ 15) und Meßgerät (Typ FH 44) stammen von der Firma Frieseke \& Höpfner, Erlangen.

Für die Messungen im Geiger-Müller-Zähler wurden von den zu untersuchenden Proben Mengen von $0,1 \mathrm{ml}$, bei Präparaten mit geringeren Aktivitäten von $0,5 \mathrm{ml}$, in Schälchen aus Messing vorsichtig eingedampft. Die Aktivitäten der Viruslösungen werden als Impulse pro Minute pro hämagglutinierender Einheit (IPM/HAE) angegeben, diejenige der chemischen Fraktionen als Impulse pro Minute pro $\mathrm{ml}(\mathrm{IPM} / \mathrm{ml})$, wobei der Nullwert stets abgezogen ist. Als Standard-Präparat wurde ein Uranylacetat-Präparat verwendet. Bei unseren Messungen waren 1000 IPM äquivalent $2,8 \cdot 10^{-3} \mu \mathrm{C}$.

4. Züchtung und Isolierung des $32 \mathrm{P}$ marki erten K P - Virus

Zur Gewinnung von radioaktiv-markiertem Virus wurden die Zell-Kulturen (s. 1.) mit 32P-haltigem Nährmedium angesetzt, 48 Stdn. bei $37^{\circ} \mathrm{C}$ bebrütet und darauf zu den Kulturen in Petrischalen $0,12 \mathrm{ml}$, zu denen in Fernbachkolben $0,7 \mathrm{ml}$ einer virushaltigen Allantois-Flüssigkeit hinzugefügt, die $256 \mathrm{HAE}$ enthielt. Nach weiterer 48 -stdg. Bebrütung bei $37^{\circ} \mathrm{C}$ wurde die Nährflüssigkeit entnommen und durch 2-maliges Zentrifugieren [5 Min. bei 2000 Umdrehungen/Min. (U/Min.), 10 Min. 3000 U/Min.] von Zellen und Zellbestandteilen gereinigt. Da sie durchschnittlich 64-128 HAE enthielt, mußte sich das zur Infektion verwendete Virus in der 32P-haltigen Gewebekultur mindestens 25-30-fach vermehrt haben. Die gereinigte Nährflüssigkeit diente als Ausgangsmaterial für die Isolierung des markierten Virus.

Die Isolierung erfolgte durch Adsorption-Elution an und von Hühnererythrocyten. Dabei gingen wir so vor, daß wir nach Adsorption des Virus aus dem Ausgangsmaterial an die Erythrocyten die virus-beladenen Zellen 3-mal mit großen Mengen eisgekühlter, gepufferter $\mathrm{NaCl}$ Lösung sowie 1-mal in Borpuffer $\left(p_{\mathrm{H}} 7,2\right)$ (jeweils 15faches Volumen der gepackten Erythrocyten) wuschen und anschließend in Borpuffer aufnahmen. Um das Virus zu eluieren, wurde die Erythrocyten-Aufschwemmung nach Zugabe von $\operatorname{RDE}^{*} 2^{1 / 2} \mathrm{Stdn}$. bei $37^{\circ} \mathrm{C}$ bebrütet. Nach Entfernung der Erythrocyten durch kurzfristiges Zentrifugieren (3 Min. 1750 U/Min.) wurde die Viruslösung $72 \mathrm{Stdn}$. gegen gepufferte $\mathrm{NaCl}$-Lösung, die wir in dieser Zeit 6-mal erneuerten, dialysiert.

* $\mathrm{RDE}=$ Rezeptorzerstörendes Enzym, ein gereinigtes Präparat der Behringwerke, Marburg.
Zur weiteren Reinigung wurden die markierten Virusteilchen nochmals in der beschriebenen Weise an Hühnererythrocyten adsorbiert, gewaschen und eluiert. Eine zweite Dialyse erfolgte jedoch nicht. Abgeschlossen wurde die Reinigung durch 10 Min. langes Zentrifugieren der Viruslösung bei $3000 \mathrm{U} / \mathrm{Min}$.

Die Volumina der gereinigten Präparate wurden so gewählt, daß gegenüber dem Ausgangsmaterial theoretisch eine 10-fache Anreicherung des Virus zu erwarten war. Praktisch wurde nach den HA-Testen diese Anreicherung aber niemals erreicht.

5. Spaltung des Virus durch $̈$ therbehandlung

Die Zerlegung des Virus in biologisch noch aktive Untereinheiten, das „Hämagglutinin“ und das „gebundene Antigen“, erfolgte mit peroxydfreiem Äther in der von $\mathrm{S}$ chäfer und $\mathrm{Zillig}{ }^{4}$ angegebenen Weise.

Als Ausgangsmaterial dienten dafür 5,0 ml einer Mischung von gereinigtem radioaktivem und gereinigtem normalem KP-Virus, die $65536 \mathrm{HAE}$ enthielt. Der Zusatz von nichtmarkiertem Virus erfolgte, um Verlauf und Ausmaß der Spaltung besser beobachten zu können. Neben der nach dem Ausschütteln abpipettierten Äther-

2-mal mit je $6 \mathrm{ml}$ Meth. Chloroform (2:1)

je 2 Stdn. bei Raum-Temperatur (RT)

extrahiert und

zentrifugiert (10 Min. $3000 \mathrm{U} / \mathrm{Min}$.)

Überstände

Sediment:

mit $6 \mathrm{ml} n$-Butanol 2 Stdn. bei RT

extrahiert und

Sediment:

2-mal mit je $6 \mathrm{ml}$ Äther gewaschen und

zentrifugiert s.o. . . . UUberstände

Sediment:

mit

$6 \mathrm{ml}$ 10-proz. Trichloressigsäure (TCE)

30 Min. im Eisbad

extrahiert und

zentrifugiert s. o. . . . . Überstand

Sediment:

2-mal mit je $6 \mathrm{ml}$ eiskalter TCE

gewaschen und

zentrifugiert s. o. . . . . Überstände

vereinigt

$=T C E-$

lösliche

Fraktion

Sediment:

3-mal mit je $6 \mathrm{ml}$ 10-proz. NaCl-Lösung 60 Min. in kochendem Wasserbad vereinigt extrahiert und zentrifugiert s.o. . . . UUberstände Fraktion

Sediment:

in $6 \mathrm{ml} 1-m . \mathrm{NaOH}$ durch kurzes $\mathrm{Er}$ -

wärmen aufgelöst... . . . . . $\}$ Rest

Schema: Chemische Fraktionierung des 32P-markierten Virus. 


\begin{tabular}{|c|c|c|c|}
\hline $\begin{array}{c}\text { P-Gehalt des } \\
\text { Nähr- } \\
\text { mediums } \\
{[\gamma \mathrm{ml}]}\end{array}$ & $\begin{array}{c}\text { IPM/HAE } \\
\text { des } \\
\text { Virus }\end{array}$ & $\begin{array}{c}\text { Verhältnis d. } \\
\text { P-Gehaltes } \\
\text { A : B }\end{array}$ & $\begin{array}{c}\text { Verhältnis } \\
\text { der spez. } \\
\text { Aktivität } \\
\text { A : B }\end{array}$ \\
\hline $\begin{array}{c}\text { A: } 54,75 \\
\text { B }: 26,08\end{array}$ & 75 & $2,1: 1$ & $1: 2,3$ \\
\hline
\end{tabular}

Tab. 1. Abhängigkeit der Virusmarkierung vom Verhältnis $32 \mathrm{P}: \mathrm{P}$ im Nährmedium.

phase, der „Hämagglutinin“- und „gebundenen Antigen“Fraktion (vgl. l. c. 4) wurde auch die nach der letzten Ätherbehandlung verbleibende Schicht zwischen Ätherund Wasserphase gewonnen und suspendiert. Sie ist als Rest bezeichnet.

\section{Chemische Fraktionierung}

Auch bei der chemischen Fraktionierung wurde die Virusmenge durch Zusatz von gereinigtem, nicht-markiertem Virus erhöht. Die Extraktion der Lipide wurde nach A d a und $\mathrm{P}$ e $\mathrm{rry}^{7}$, diejenige der in kalter Trichloressigsäure löslichen Phosphorverbindungen (TCE-lösliche Fraktion) nach D a vi d s o ${ }^{8}$ und die Nucleinsäure-Extraktion (NS-Fraktion) nach Davidson und Smel1 i e 9 durchgeführt. Im einzelnen verlief der Arbeitsgang, wie in Schema S. 182 dargestellt.

Die einzelnen Fraktionen wurden vor der Aktivitätsbestimmung zur Entfernung korpuskulärer Verunreinigungen nochmals $10 \mathrm{Min}$. bei $3000 \mathrm{U} / \mathrm{Min}$. zentrifugiert. Die gemessene Aktivität ist jeweils auf ein Einheitsvolumen von $6 \mathrm{ml}$ bezogen.

7. Phos phorbestim mung

Die Bestimmung des Phosphors erfolgte nach $\mathrm{F}$ is ke und $\mathrm{Subb}$ a row $\mathbf{1 0}$.

\section{Ergebnisse}

1. Die Bedeutung des Verhältnisses ${ }^{32} \mathrm{P}$ : $\mathrm{P}$ im Nährmedium für die Virusmarkierung

Die Versuche zur Markierung des KP-Virus mit ${ }^{32} \mathrm{P}$ wurden — wie bereits vorher beschrieben - so angelegt, daß wir zuerst den Wirtszellen in der Kultur radioaktives Phosphat anboten und erst darauf in diesem System das Virus zur Vermehrung brachten. Dabei wurde versucht, den Einbau von radioaktivem Phosphor in das Virus dadurch zu steigern, daß möglichst viel ${ }^{32} \mathrm{P}$ und möglichst wenig nicht-radioaktiver Phosphor im Nährmedium zur Ver-

7 G. L. A d a u. B. T. P erry, Austral. J. exp. Biol. med. Sci. 32, 453 [1954].

8 J. N. D a vids on, S. C. Frazer u. W. C. H u t c h in s o n, Biochem. J. 49, 311 [1951].

9 I. N. D a vid s on u. R. M. S m ellie, Biochem. J. 52, 594 [1952].

10 C. H. Fiske u. Y. S u b b a row, J. biol. Chemistry 66, 375 [1925].

\begin{tabular}{|c|c|c|c|}
\hline $\begin{array}{c}\text { Eingesetzte } \\
\text { Aktivität } \\
\text { "IC/ml }\end{array}$ & IPM/HAE & $\begin{array}{c}\text { Steigerung } \\
\text { der }{ }^{32} \text { P-Akti- } \\
\text { vität des } \\
\text { Mediums } \\
\text { (Faktor) }\end{array}$ & $\begin{array}{c}\text { Steigerungd. } \\
\text { spez. Radio- } \\
\text { aktivität } \\
\text { des Virus } \\
\text { (Faktor) }\end{array}$ \\
\hline 41,5 & 48,5 & & \\
83 & 121 & 2 & 2,4 \\
166 & 246 & 4 & 5,0 \\
483 & 550 & 11,6 & 11,4 \\
1500 & 1495 & 36,1 & 30,8 \\
\hline
\end{tabular}

Tab. 2. Abhängigkeit der Virusmarkierung von der 32PMenge im Nährmedium.

fügung gestellt wurde. Dieses Vorgehen konnte aber nur dann Erfolg haben, wenn die Verminderung des im Nährmedium enthaltenen Phosphates die Virusvermehrung nicht wesentlich beeinträchtigte.

Um dies nachzuprüfen, wurden zwei Kulturen angesetzt. Die eine (A) enthielt normales Nährmedium, die andere (B) Nährmedium, bei dem in der Earle-Lösung der Phosphatanteil $\left(0,14 \mathrm{~g} \mathrm{Na}_{2} \mathrm{PO}_{4} \cdot \mathrm{H}_{2} \mathrm{O} / 1000 \mathrm{ml}\right)$ fehlte. Beiden Kulturen wurde beim Ansetzen die gleiche 32PMenge $(1500 \mu \mathrm{C})$ sowie $48 \mathrm{Stdn}$. später die gleiche Virusdosis hinzugefügt.

Die Zellen von A und B zeigten in ihrem züchterischen Verhalten keinen Unterschied. Ebenso war die Virusausbeute mit 64 HAE in beiden Kulturen die gleiche. Große Unterschiede ergaben sich aber bei den spezifischen Radioaktivitäten der aus ihnen gewonnenen gereinigten Virusproben (s. Tab. 1). Bei gleicher eingesetzter Radioaktivität stieg die Menge an eingebautem ${ }^{32} \mathrm{P}$ im gleichen Verhältnis, wie der Gehalt an nicht-radioaktivem Phosphor heruntergesetzt wurde.

Auf Grund dieses Untersuchungsergebnisses wurde bei allen weiteren Versuchen zur Markierung des KP-Virus nur phosphat-freie Earle-Lösung in den Nährmedien der Gewebekulturen verwendet. Inwieweit sich die Markierung durch Entfernung des restlichen in den Nährlösungen vorhandenen Phosphates, das aus Pferdeserum und Embryonalextrakt herstammt, noch steigern läßt, wurde nicht geprüft.

In einem weiteren Experiment wurde untersucht, in welchem Maße eine Erhöhung des ${ }^{32} \mathrm{P}-Z$ Zusatzes im P-armen Nährmedium sich auf den Markierungsgrad des Virus auswirkt. Die angesetzten Kulturen unterschieden sich nur in ihrem ${ }^{32} \mathrm{P}-\mathrm{Gehalt}$.

Wie Tab. 2 ausweist, wurde dabei in dem geprüften Bereich eine nahezu lineare Beziehung zwischen der bei der Züchtung eingesetzten und der in das Virus eingebauten ${ }^{32} \mathrm{P}-\mathrm{Menge}$ festgestellt. $\mathrm{Zu}$ ähnlichen Ergebnissen kamen auch Graham und 
McClelland ${ }^{1}$ sowie Li u und Mitarbb. ${ }^{3}$ bei ihren Experimenten mit Influenza-Virus.

Die höchste spezifische Radioaktivität, die unter Beachtung der bisher getroffenen Feststellungen beim KP-Virus erreicht wurde, betrug 1495 IPM/HAE.

2. Wirkung verschiedener ${ }^{32} \mathrm{P}-\mathrm{Men}$ gen auf Gewebekulturen und VirusA usbeute

Auf Grund der Erfahrungen, die insbesondere Graham und $\mathrm{McClelland}{ }^{1}$ bei ihren Markierungs-Versuchen machten, mußte man damit rechnen, daß zu große Mengen von Isotopen-Material die Wirtszellen beeinträchtigen und die Virusvermehrung stören. Wie die genannten Autoren, die ihr Phosphat allerdings von einer anderen Stelle bezogen, feststellten, schädigten in ihren Versuchen bereits $0,2 \mu \mathrm{C}{ }^{32} \mathrm{P}$ pro Ei den Embryo. Li u und Mitarbb. ${ }^{3}$ gingen in den Experimenten mit entembryonierten Eiern nicht über $1000 \mu \mathrm{C}$ pro Kultur $=111 \mu \mathrm{C} / \mathrm{ml}$ Nährlösung hinaus. In unseren Gewebekulturen ließ sich zwar nach Zusatz von $2000 \mu \mathrm{C} / \mathrm{ml}$ mikroskopisch keine Schädigung der Zellen feststellen, es wurde aber bereits bei einer Menge von $1500 \mu \mathrm{C} / \mathrm{ml}$ eine deutliche Hemmung der Virusvermehrung beobachtet. Die Ausbeute an Virus betrug in diesem Falle nur etwa $10 \%$ der unter normalen Züchtungsbedingungen durchschnittlich erreichten Menge. Bei Einsatz von $500 \mu \mathrm{C} / \mathrm{ml}$ war die Virusvermehrung nicht gestört.

3. Prüfung des isolierten, markierten Virus auf Reinheit

Der erzielte Markierungs-Effekt läßt sich nur sicher beurteilen, wenn dafür gesorgt wird, daß die gemessene Aktivität zum überwiegenden Teil von VirusPartikeln und nicht von Verunreinigungen der VirusLösung herrührt.

Um dies weitgehend sicherzustellen, wurde ein Reinigungsverfahren gewählt, das nach unseren bisherigen Erfahrungen sowie nach den Untersuchungen von Li u und Mitarbb. ${ }^{3}$ hochgradig reine Viruspräparate liefert. Nicht mit den Virusteilchen verbundene ${ }^{32} \mathrm{P}$-Träger werden dabei nahezu vollständig entfernt.

So konnte in einem Kontroll-Versuch gezeigt werden, daß aus ${ }^{32} \mathrm{P}$-haltigem Nährmedium einer nichtinfizierten Gewebekultur nur Spuren von radioaktivem Material durch den üblichen Aufarbeitungsgang hindurchgeschleppt werden. Die Radioaktivität des dabei erhaltenen virus-freien Endproduktes betrug

\begin{tabular}{|c|c|c|}
\hline & $\begin{array}{c}\mathrm{IPM} / \mathrm{ml} \\
\text { Überstand }\end{array}$ & {$[\%]$} \\
\hline $\begin{array}{c}\text { Ansatz mit Antiserum } \\
\text { Ansatz mit Normal- } \\
\text { Serum }\end{array}$ & 2780 & 100 \\
7,3 \\
\hline
\end{tabular}

Tab. 3. Restliche Radicakivität im Überstand nach Adsorption des markierten Virus an Erythrocyten.

nur $<0,1 \%$ der Aktivität eines Viruspräparates, das aus einem parallelen, aber infizierten GewebekulturAnsatz gewonnen war.

Der endgültige Beweis dafür, daß der überwiegende Teil des in unseren Viruspräparaten festgestellten ${ }^{32} \mathrm{P}$ tatsächlich mit den Virusteilchen verbunden ist, wurde durch einen weiteren Versuch erbracht.

$\mathrm{Zu} 0,5 \mathrm{ml}$ eines gereinigten, markierten Viruspräparates mit $32 \mathrm{HAE}$ wurden $0,5 \mathrm{ml} \mathrm{KP}$-Antiserum vom Huhn in der Verdünnung 1:40 zugesetzt. Ein zweites Röhrchen enthielt die gleiche Virus-Menge, aber an Stelle von Anti-KP-Serum normales Hühnerserum der gleichen Konzentration. Beide Proben wurden 30 Min. bei ZimmerTemperatur gehalten und darauf jeder $0,25 \mathrm{ml}$ gewaschene, gepackte Hühnererythrocyten zugesetzt. Nach weiterem 20 Min. langem Stehen bei Zimmer-Temperatur wurden bei beiden Proben die Blutkörperchen abzentrifugiert und dann die Radioaktivitäten der Überstände gemessen.

Da das KP-Virus nur in Gegenwart von Normalserum, nicht aber bei Anwesenheit von KP-Antiserum an Erythrocyten adsorbiert wird, darf auch das Isotop, wenn der Träger des in unseren Präparaten vorliegenden ${ }^{32} \mathrm{P}$ mit den Virusteilchen identisch ist, nur unter den gleichen Bedingungen eine Bindung mit den Blutkörperchen eingehen. Das ist, wie das in Tab. 3 wiedergegebene Ergebnis zeigt, tatsächlich der Fall. Im Ansatz mit Normalserum bleibt nur eine relativ geringe Radioaktivität $(7,3 \%)$ im Überstand zurück. Sie ist wahrscheinlich zum Teil noch auf nicht-adsorbierte, radioaktive Virusteilchen zurückzuführen, weil eine 100-proz. Adsorption der Viruspartikel in derartigen Versuchen erfahrungsgemäß nie erreicht wird.

Die Frage war nun, in welche Bestandteile des Virusteilchens der zugesetzte radioaktive Phosphor cingebaut wird.

4. Wirkung des eingebauten radioaktiven Phosphors auf die biologischen Eigenschaften des Virus

$\mathrm{Da}{ }^{32} \mathrm{P}$ beim Zerfall in Schwefel übergeht, war anzunehmen, daß die Bestandteile des Virus, in die das Isotop eingebaut ist, mit forschreitendem Zerfall des- 


\begin{tabular}{|c|c|c|c|c|}
\hline \multicolumn{3}{|c|}{ Markiertes Virus } & \multicolumn{2}{|c|}{ Kontroll-Virus } \\
\hline \multicolumn{3}{|c|}{ Präp. 1 (436 IPM/HAE) } & \multicolumn{2}{|r|}{ Präp. 1} \\
\hline $\begin{array}{c}\text { Alter des } \\
\text { Virus-Präp. }\end{array}$ & HAE & $\begin{array}{l}\text { Infekt.-Titer } \\
(\mathrm{PBE})\end{array}$ & $\mathrm{HAE}$ & $\begin{array}{l}\text { Infekt.-Titer } \\
\text { (PBE) }\end{array}$ \\
\hline Frisch & 8 & $3,2 \cdot 10^{6}$ & 8 & $4,8 \cdot 10^{6}$ \\
\hline $\begin{array}{l}\text { Nach } \\
4 \text { Tagen }\end{array}$ & 8 & $5,2 \cdot 10^{5}$ & 8 & $4,3 \cdot 10^{6}$ \\
\hline \multicolumn{3}{|c|}{ Präp. 2 (114 IPM/HAE) } & \multicolumn{2}{|c|}{ Präp. 2} \\
\hline $\begin{array}{c}\text { Alter des } \\
\text { Virus-Präp. }\end{array}$ & HAE & $\begin{array}{c}\text { Infekt.- } \\
\text { Titer (PBE) }\end{array}$ & $\mathrm{HAE}$ & $\begin{array}{c}\text { Infekt-- } \\
\text { Titer (PBE) }\end{array}$ \\
\hline Frisch & 8 & $3,3 \cdot 10^{5}$ & 8 & $8,9 \cdot 10^{5}$ \\
\hline $\begin{array}{l}\text { Nach } \\
12 \text { Tagen }\end{array}$ & 8 & $1,9 \cdot 10^{t}$ & 8 & $3,7 \cdot 10^{5}$ \\
\hline
\end{tabular}

Tab. 4. Wirkung des eingebauten ${ }^{32} \mathrm{P}$ auf Infektiosität und HA-Aktivität des Virus.

selben ihre biologische Funktion nicht mehr erfüllen können. Aus dem Ausfall der betreffenden Funktionen mußte sich dann ein Hinweis auf den markierten Virusbestandteil gewinnen lassen.

$\mathrm{Zu}$ den das KP-Virus kennzeichnenden biologischen Aktivitäten gehört neben der Infektiosität die hämagglutinierende Wirksamkeit. Es wurde untersucht, ob eine von beiden beim radioaktiv-markierten Virus im Laufe der Zeit stärker abnimmt als beim normalen, nicht-markierten Virus. Tab. 4 gibt die Ergebnisse dieser Experimente wieder. Es zeigte sich dabei, daß wohl die infektiöse, nicht aber die hämagglutinierende Wirksamkeit beim ${ }^{32} \mathrm{P}$-haltigen Virus beeinträchtigt wird. Die Infektionsaktivität der radioaktiven Präparate ging im ersten Versuch innerhalb von 4 Tagen um $84 \%$, im zweiten Versuch mit schwächer markiertem Virus innerhalb von 12 Tagen um $94 \%$ zurück. Beim nicht-markierten Virus war lediglich nach 12-tägiger Aufbewahrung ein gewisser Infektionsrückgang festzustellen, der aber nur $\sim 50 \%$ betrug.

Dieses Ergebnis macht es wahrscheinlich, daß ${ }^{32} \mathrm{P}$ zwar nicht in den für die Hämagglutination verantwortlichen Bestandteil des Virus, wohl aber in eine andere, für die Vermehrung des Erregers besonders wichtige Komponente eingebaut wird.

\section{Chemische Fraktionierung des markierten Virus}

Klarer als durch die beschriebene biologische Methode ließ sich durch chemische Fraktionierung der

\begin{tabular}{|l|c|c|}
\hline \multicolumn{1}{|c|}{ Präparat } & IPM/ml & {$[\%]$} \\
\hline Ausgangsprodukt & 43682 & 100 \\
Ätherphase & 9817 & 22,75 \\
Hämagglutinin & 1313 & 3,0 \\
Gebundenes & 9117 & 21,0 \\
$\begin{array}{l}\text { Antigen } \\
\text { Rest }\end{array}$ & 8367 & 19,2 \\
Summe & 28614 & 65,95 \\
\hline
\end{tabular}

Tab. 6. Verteilung des eingebauten ${ }^{32} \mathrm{P}$ auf die biologischen Untereinheiten des Virus.

Virus-Elementarteilchen die Verteilung des ${ }^{32} \mathrm{P}$ im Virus ermitteln.

Wie aus den in Tab. 5 wiedergegebenen Werten hervorgeht, fand sich die Hauptmasse des radioaktiven Phosphors in der Lipid-Fraktion des Virus, die im Durchschnitt etwa 65\% der im Ausgangsmaterial vorliegenden Menge enthielt. Wesentlich geringer war der Gehalt der TCE-löslichen Fraktion. Er lag zwischen 3,8 und 10 Prozent. Für die NS-Fraktion wurde zwischen 6,8 und $16,2 \%{ }^{32} \mathrm{P}$ gefunden, es fällt aber auf, daß sich der Isotopen-Anteil der Reste jeweils komplementär zu diesen Werten verhält. Addiert man die Prozentzahlen der beiden Fraktionen, so kommt man auf einen Wert von $\sim 21$ Prozent. Die Erklärung hierfür ist wohl darin zu suchen, daß das benützte NS-Extraktions-Verfahren nach Angaben von Davidson und Smellie ${ }^{9}$ sowie nach eigenen Erfahrungen zwar reine hochmolekulare $\mathrm{Nu}$ cleinsäure-Präparate, aber in wechselnden Ausbeuten liefert und daß deshalb erst die Summe aus den Radioaktivitäten der NS- und Rest-Fraktion (21\%) dem tatsächlichen Anteil der Nucleinsäure an der Gesamtaktivität des Viruspartikels nahekommt. ${ }^{32} \mathrm{P}$ wird demnach unter unseren Versuchsbedingungen zum größten Teil in die Phosphor-Lipoide und daneben noch in beträchtlicher Menge in die Nucleinsäure des Virus, die dem Ribosetyp angehört ${ }^{11}$, eingebaut.

Die Lipide scheinen nach unseren heutigen Kenntnissen im wesentlichen als Kittsubstanz im Viruspartikel zu dienen. Entfernt man sie, so kann man als Untereinheiten des Virus das nucleinsäure-freie, hämagglutination-bewirkende „Hämagglutinin“ sowie das „gebundene Antigen“ isolieren, das der alleinige Träger der Ribonucleinsäure im Elementarteilchen ist ${ }^{4}$ und deshalb sehr wahrscheinlich das

11 W. Zillig, W. Schäfer u. S. Ullmann, Z. Naturforschg. 10 b, 199 [1955]. 


\begin{tabular}{|l|c|c|c|c|c|c|c|}
\hline & $\begin{array}{c}\text { Versuch 1 } \\
\text { IPM/ml }\end{array}$ & {$[\%]$} & $\begin{array}{c}\text { Versuch 2 } \\
\text { IPM/ml }\end{array}$ & {$[\%]$} & $\begin{array}{c}\text { Versuch 3 } \\
\text { IPM/ml }\end{array}$ & {$[\%$ \% $]$} & $\begin{array}{c}\text { Durchschnitt } \\
\% \text { vom Ausgang }\end{array}$ \\
\hline Ausgangs-Präparat & 42690 & 100 & 934 & 100 & 530 & 100 & 100 \\
Lipide & 25412 & 59,5 & 618,5 & 66,2 & 378 & 70,0 & 65,2 \\
TCE-lösl. Fraktion & 4320 & 10,1 & 36 & 3,84 & 28 & 5,31 & 6,41 \\
NS-Fraktion & 6945 & 16,2 & 120 & 12,8 & 36 & 6,8 & 11,6 \\
Rest & 2022 & 4,7 & 58 & 6,2 & 88 & 16,15 & 9,01 \\
Summe & & 90,5 & & 89,04 & & 98,26 & 92,52 \\
\hline
\end{tabular}

Tab. 5. Verteilung des eingebauten ${ }^{2} 2 \mathrm{P}$ auf die einzelnen phosphorhaltigen Verbindungen des Virus.

eigentliche vermehrungsfähige Material des Virus repräsentiert. Wegen der Unterschiede im chemischen Aufbau kann von diesen beiden Untereinheiten nur das „gebundene Antigen“ größere Mengen von ${ }^{32} \mathrm{P}$ enthalten.

Ein Versuch, bei dem wir radioaktiv-markiertes Virus durch Behandlung mit Äther zerlegten und darauf „Hämagglutinin“ und „gebundenes Antigen“ in weitgehend reiner Form gewannen, bestätigte dies. Wie aus früheren Experimenten bekannt, ist bei diesem Verfahren allerdings eine quantitative Ausbeute an Untereinheiten nicht zu erzielen. Vor allem beim „Hämagglutinin“ muß immer ein gewisser Verlust in Kauf genommen werden.

Trotz der dadurch gegebenen Einschränkungen läßt sich aus den gefundenen Werten (s. Tab. 6) aber ersehen, daß das „Hämagglutinin“ — wie erwartet — wesentlich weniger Aktivität enthält als das ,gebundene Antigen“. Der im letzteren gefundene Anteil beträgt, bezogen auf die Aktivität des eingesetzten ungespaltenen Virus, 21 Prozent. Dieser Wert steht wiederum in guter Übereinstimmung mit dem Aktivitäts-Anteil, der nach den oben angestellten Überlegungen der Gesamtnucleinsäure des markierten Virus zukommt.

Bei der gefundenen Verteilung des radioaktiven Phosphors im Elementarteilchen wird es verständlich, daß durch den Isotopenzerfall wohl das Vermehrungs-, nicht aber das HA-Vermögen des Virus geschädigt wird.

Nach Gewinnung der chemischen Fraktionen bot sich noch die Möglichkeit, die spezifischen Radioaktivitäten der Lipid- und NS-Fraktionen, bezogen auf ihren Phosphor-Gehalt, zu ermitteln. Dabei ergaben sich im Versuch 1 (s. Tab. 5) folgende Werte:

$$
\begin{array}{ll}
\text { Lipide } & 475,7 \mathrm{IPM} / \gamma \mathrm{P}, \\
\text { NS } & 442,7 \mathrm{IPM} / \gamma \mathrm{P} .
\end{array}
$$

Das Verhältnis zwischen ${ }^{32} \mathrm{P}$ und nicht-radioaktivem Phosphor ist also in Lipid- und NS-Fraktion annähernd gleich groß.

\section{Besprechung der Ergebnisse}

Durch Züchtung des KP-Virus in Gewebekulturen, denen ${ }^{32} \mathrm{P}$ zugesetzt wurde, gelang es, verhältnismäßig große Mengen des Isotops in den Erreger einzubauen. Es wurden spezifische Aktivitäten bis zu 1500 IPM/HAE erzielt. Demgegenüber betrug der Höchstwert, der bei Influenza-Virus nach Züchtung in ${ }^{32} \mathrm{P}$-haltigen, entembryonierten Eiern erreicht wurde ${ }^{3}$, nur $131 \mathrm{IPM} / \mathrm{HAE}$. Die Markierung war beim KPVirus um so höher, je weniger nicht-radioaktiver und je mehr radioaktiver Phosphor angeboten wurde. Bei gleichbleibend niedrigem Spiegel von nicht-radioaktivem Phosphor war die eingebaute ${ }^{32} \mathrm{P}$-Menge in einem großen Bereich nahezu linear abhängig von der eingesetzten Isotopen-Dosis. Eine Störung der Virusvermehrung war erst zu beobachten, wenn die Gewebekulturen in der Nährflüssigkeit Aktivitäten von mehr als $1000 \mu \mathrm{C} / \mathrm{ml}$ enthielten.

Der Einbau des ${ }^{32} \mathrm{P}$ erfolgte vor allem in den Lipid- $(\sim 65 \%)$ und in den Ribonucleinsäure-Anteil $(\sim 21 \%)$ des KP-Virus. Eine ähnliche Verteilung des ${ }^{3} \cdot \mathrm{P}$ fanden auch Li u und Mitarbb. ${ }^{3}$ beim InfluenzaVirus, während $\mathrm{Graham}{ }^{12}$ bei diesem Erreger in der Nucleinsäure eine 4-mal höhere, $\mathrm{Hoyle}$ und Mitarbb. ${ }^{2}$ eine 3-mal höhere Radioaktivität als in den Lipiden feststellten. Dieser Unterschied ist nach Ansicht von Li u und Mitarbb. ${ }^{3}$ dadurch bedingt, daß die letztgenannten Autoren das radioaktive Phosphat erst kurz vor oder sogar erst nach dem Anlauf der Virusvermehrung injizierten.

Von den durch Ätherbehandlung gewonnenen Untereinheiten des KP-Virus enthielt das nucleinsäurehaltige ,gebundene Antigen“ große, das „Hämagglutinin" nur sehr geringe Mengen von ${ }^{32} \mathrm{P}$. Damit steht offenbar in Zusammenhang, daß durch den Zerfall des ${ }^{32} \mathrm{P}$ wohl die infektiöse, nicht aber die hämagglutinierende Wirkung des Virus geschädigt wird.

Die Gründe für die gute Eignung der Gewebe-

12 A. F. Gr a h a m, Can. J. Res. 28, 186 [1950]. 
kultur zur Erzeugung von hochmarkiertem KP-Virus sind einmal darin zu suchen, daß der größte Teil der in ihr enthaltenen Zellen die Möglichkeit hat, ${ }^{32} \mathrm{P}$ aufzunehmen und für die Virusinfektion zugänglich und empfänglich ist. Weiterhin wissen wir, daß sich die Zellen und insbesondere die Fibroblasten in der Kultur gut vermehren und deshalb hier einen hohen Stoffwechsel besitzen. Sie werden daher auch eine verhältnismäßig große Menge von angebotenem ${ }^{32} \mathrm{P}$ in sich aufnehmen, den sie an das Virus weiterreichen. Hinzu kommt schließlich noch, daß die Kulturzellen eine große Toleranz gegenüber dem benützten ${ }^{32}$ P-Präparat zeigen und man deshalb bei ihnen mit hohen Isotopen-Dosen arbeiten kann. Bei entembryonierten und vor allem bei embryohaltigen Eiern liegen die Verhältnisse demgegenüber wesentlich ungünstiger. Bei den letzteren muß man vor allem da- mit rechnen, daß der größte Teil des zugeführten ${ }^{32} \mathrm{P}$ in Zellen, die nicht an der Virusvermehrung teilnehmen, abwandert und deshalb für den Einbau in den Erreger verlorengeht.

Die mit dem beschriebenen Verfahren beim KPVirus erzielte ${ }^{32} \mathrm{P}-$ Markierung ist so hoch, daß nunmehr auch bei dieser tierpathogenen Virusart eine eingehende Untersuchung des Vermehrungsprozesses mit Hilfe radioaktiv gekennzeichneter Elementarteilchen lohnend erscheint.

Herrn Dr. Ch. L a nd s chü t $\mathrm{z}$ danken wir für wertvolle Hinweise, Fräulein I. K l o etzel für ihre ausgezeichnete Hilfe bei der Durchführung der Versuche. Die Untersuchungen wurden mit Mitteln des Bundesministeriums für Ernährung, Landwirt$\mathrm{sch}$ aft und Forsten und der Deutschen For $\mathrm{sch}$ ung sgemeins chaft durchgeführt.

\section{Die Anwendung von Ionenaustauschern zur Viruspräparation}

\section{Mitt.: Der Einfluf der Austauschereigenschaften auf die Adsorption von Influenza-Virus}

Von H. D. Matheka und O. Armbruster

Aus der Bundesforschungsanstalt für Viruskrankheiten der Tiere, Tübingen

(Z. Naturforschg. 11 b, 187-193 [1956]; eingegangen am 3. Februar 1956)

Die Anwendung von Ionenaustauschern erlaubt es, Allantoisflüssigkeit von Hühnerembryonen, die mit Influenzavirus infiziert sind, zu fraktionieren und zu reinigen. Aus der Ausgangslösung werden $80 \%$ der stickstoffhaltigen Bestandteile, 95\% des Phosphors und über $80 \%$ der Kohlehydrate durch Dialyse entfernt, was sich bei der Auftrennung am Ionenaustauscher günstig bemerkbar macht. Beim Vergleich von Austauschern verschiedener Basizität zeigen stark basische Anionenaustauscher im Bereich von $p_{\mathrm{H}} 6-7$ die günstigsten Eigenschaften. Der Vernetzungsgrad hat nur geringen Einfluß auf die Adsorption von Virus.

$\mathrm{D}$ ie Ionenaustauscher haben in der Chemie im letzten Jahrzehnt neben anderen Hilfsmitteln eine tragende Stellung bei der Präparation und Reinigung von Substanzen und komplexen Gemischen eingenommen. Sie haben auch Anwendung auf dem Gebiet der Naturstoffe und der Biochemie gefunden. Mehrere Arbeiten ${ }^{1-8}$ sind bekannt, in denen gezeigt wurde, daß auch Virussuspensionen mit Hilfe von Ionenaustauschern gereinigt werden konnten. Neuro-

1 R. H. M u lle r, Proc. Soc. exp. Biol. Med. 73, 239 [1950].

2 G. A. L o Grip p o, l. c. 74, 208 [1950].

3 R. H. M uller u. H. M. Ros e, l. c. 80, 27 [1952].

4 T. Puck u. B. Sagik, J. exp. Med. 97, 807 [1953].

5 G. Ci a c cio, G. B oretti u. A. Gallo, Mikrobiol. Kongr. Rom (1953) S. 85. trope Viren wie auch Influenza-Virus wurden zu diesen Versuchen herangezogen.

Da das Influenza-Virus den meisten Autoren als Ausgangsmaterial vorgelegen hatte, benutzten es auch wir als Modell zur Austestung der Ionenaustauscher. Besonderen Wert legten wir auf die Feststellung von Unterschieden im Verhalten von Virussuspensionen gegenüber Ionenaustauschern im Hinblick auf die Basizität, den Vernetzungsgrad und die

6 S. M. Kelly, Amer. J. publ. Health Nation's Health 43, 1532 [1953].

7 Y. S awai, H. Yanaka, M. A. M a kinou. K. Ki k u chi, Jap. J. Bacteriol. 9, 509 [1954]; ref. Biol. Abstr. 29, 14228 [1954].

8 K. T a kemoto, Proc. Soc. exp. Biol. Med. 85, 670 [1954]. 